Tropical Journal of Pharmaceutical Research February 2016; 15 (2): 363-369

ISSN: $1596-5996$ (print); 1596-9827 (electronic)

(C) Pharmacotherapy Group, Faculty of Pharmacy, University of Benin, Benin City, 300001 Nigeria.

All rights reserved.

Available online at http://www.tjpr.org

Original Research Article

http://dx.doi.org/10.4314/tjpr.v15i2.20

\title{
Pharmacokinetics of Caffeic Acid from Methanol Seed Extract of Syzygium cumini L in Rats
}

\author{
Muhammad Islam ${ }^{1}$, Naureen Shehzadi ${ }^{1}$, Muhammad Salman ${ }^{2}$, Fakhra Zahid ${ }^{1}$, \\ Humaira M Khan ${ }^{3}$, Sohail Amjad ${ }^{1}$, Muhammad T Khan ${ }^{1}$, Muhammad Z Danish', \\ Nadeem I Bukhari ${ }^{1}$, Khalid Hussain ${ }^{1 *}$ \\ ${ }^{1}$ University College of Pharmacy, University of the Punjab, Allama lqbal Campus, Lahore-54000, Pakistan, ${ }^{2}$ School of \\ Pharmaceutical Sciences, Universiti Sains Malaysia, Penang-11800, Malaysia, ${ }^{3}$ Lahore College for Women University, Lahore- \\ 14860, Pakistan
}

${ }^{*}$ For correspondence: Email: hussain_761@yahoo.com; Tel: +924299211617; Fax: +924299211624

Received: 15 March 2015

Revised accepted: 17 December 2015

\begin{abstract}
Purpose: To describe caffeic acid-based pharmacokinetics of methanol extract of seed of Syzygium cumini $L$. in rats.

Methods: A dose of the extract (500 mg, equivalent to $37.135 \mathrm{mg}$ caffeic acid) was administered orally to 6 male Wister rats, weighing $200 \pm 10 \mathrm{~g}$. Blood samples $(0.5 \mathrm{~mL})$, collected from the tail vein at 0,15 , 30, 60, 120, 240 and $720 \mathrm{~min}$, were processed and analyzed using high performance liquid chromatography and detected with florescent light detector (FLD).

Results: Following the administration of the extract, caffeic acid achieved maximum plasma concentration (5.96 $\pm 0.49 \mu \mathrm{g} / \mathrm{mL})$ in $1.0 \mathrm{~h}$ which was also the time to achieve maximum concentration $\left(T_{\text {max }}\right)$. Mean resident time $(M R T)$ and half-life $\left(t_{1 / 2}\right)$ were $4.092 \pm 0.94 h$ and $0.14 \pm 0.01 \mathrm{~h}$, respectively. Conclusion: The results indicate that absorption of caffeic acid from the oral route is fast, but lower amounts are absorbed. The method developed for the extraction of caffeic acid from the plasma and HPLC determination may be useful in establishing phyto-bioequivalence between Syzygium cumini seed products.
\end{abstract}

Keywords: Caffeic acid, Pharmacokinetics, Syzygium cumini, Phytobioequivalence, Absorption

Tropical Journal of Pharmaceutical Research is indexed by Science Citation Index (SciSearch), Scopus, International Pharmaceutical Abstract, Chemical Abstracts, Embase, Index Copernicus, EBSCO, African Index Medicus, JournalSeek, Journal Citation Reports/Science Edition, Directory of Open Access Journals (DOAJ), African Journal Online, Bioline International, Open-J-Gate and Pharmacy Abstracts

\section{INTRODUCTION}

Syzygium cumini L. (Myrtaceae), locally known as Jamun, is well-known plant for its nutritional and medicinal properties. Almost every part of the plant is used medicinally [1-2], however, the seeds in sweetish-sour berries are the most important one being used to treat a variety of ailments especially diabetes mellitus [3]. Seed powder in combination with mango kernels is reported to be effective for treating diarrhea, dysentery, spleen enlargement and enurea $[3,4]$.
Other parts of the plant have also been exploited by natural product researchers for their antioxidant, anti-inflammatory, gastroprotective, anti-fertility [3], antibacterial [5,6], antipyretic [7], anticonvulsant [8], and antineoplastic [9] potentials. To the best of our literature review, no report on pharmacokinetics studies of extracts of the seed was found.

Pharmacokinetics evaluation of the drug has a pivotal role in selection of its route of administration, dose, dosing interval and 
exposure, etc. In the recent past, this neglected aspect of natural products has grasped the attention of researchers, which is evident by a number of pharmacokinetics studies of plantbased products/extracts [10-12]. Unlike pharmaceuticals, phytopharmaceuticals are a mixture of known and mostly unknown components, hence are difficult to be investigated for pharmacokinetics. Another limitation is lack of analytical methods and unavailability of analytical standards. Li et al categorized markers into eight categories, which may be used as analytical standards [13].

The seeds contain caffeic acid which is a polyphenolic compound possessing antioxidant [14], immunomodulatory [15], antimicrobial [16], antiaging [17], anti-inflammatory [18] and antidiabetic [19] activities. Therefore, the aim of this study is to use caffeic acid (Figure 1) as an analytical marker to investigate its pharmacokinetics from extracts of seeds of Syzygium cumini.<smiles>O=C(O)/C=C/c1ccc(O)c(O)c1</smiles>

Figure 1: Structural formula of caffeic acid

\section{EXPERIMENTAL}

\section{Chemicals and solvents}

Caffeic acid (Sigma Aldrich), HPLC grade methanol and acetonitrile (Merck, Germany), EDTA coated blood collection tubes and disposable syringes (BD) and $0.45 \mu \mathrm{m}$ pore PTFE filters (Whatman, Maidstone, England) were procured from the local supplier. Ultrapurified water (HPLC grade) was prepared in the laboratory.

\section{Plant materials}

In May 2010, $28 \mathrm{~kg}$ ripe berries of the plant were purchased from the fruit market of Multan, Pakistan. The material was authenticated by Prof Dr Zaheer ud Din Khan (a taxonomist), Department of Botany, Government College University (GCU), Lahore, Pakistan. A voucher specimen (no. G. C. Bot. Herb 853) was deposited in the herbarium of GCU. The seeds were separated, washed with water and dried in an oven at $50{ }^{\circ} \mathrm{C}$. The material was then crushed using colloidal mill, dried under shade for 4 weeks and pulverized. Five hundred grams powdered material was extracted sequentially by Soxhlet apparatus using petroleum ether, chloroform and methanol. The extracts were filtered and dried in vacuo at $40^{\circ} \mathrm{C}$.

\section{Development and validation of HPLC method}

\section{Extraction of caffeic acid from plasma}

Rat plasma $(500 \mu \mathrm{L})$ was spiked with $500 \mu \mathrm{L}$ caffeic acid solution $(100 \mu \mathrm{g} / \mathrm{mL})$ and mixed by vortex for $1 \mathrm{~min}$. Then, $200 \mu \mathrm{L}$ acetonitrile was added and mixed by vortex for $5 \mathrm{~s}$. Finally, 800 $\mu \mathrm{L}$ methanol was added and mixed by vortex for 5 s. The contents were subjected to centrifugation at $2700 \mathrm{rpm}$ for $10 \mathrm{~min}$ at $25{ }^{\circ} \mathrm{C}$. The supernatant was collected, dried with liquid nitrogen and the residue was reconstituted with $100 \mu \mathrm{L}$ methanol.

\section{High Performance Liquid Chromatography (HPLC)}

HPLC system $(1200$ series, Agilent Technologies, Waldronn, Germany), equipped with degasser (G1379 A), quaternary pump (G1310 A), auto sampler (G1329 A), column oven (G1316 A) and florescent light detector (G $1321 \mathrm{~A}$ ) was used in the study. The system was operated with LC/MS ChemStation software.

\section{Chromatographic conditions}

A volume of the sample/standard $(20 \mu \mathrm{L})$ was eluted through column - Eclipse X DB-C18 (5 $\mu \mathrm{m}, 4.6 \times 150 \mathrm{~mm}$ ) - at flow rate of $1.0 \mathrm{~mL} / \mathrm{min}$, using isocratic mobile phase; water : acetonitrile : acetic acid $(79: 20: 1.0, \mathrm{v} / \mathrm{v} / \mathrm{v})$. The column was maintained at $25{ }^{\circ} \mathrm{C}$ and the detection was carried out using florescent light detector (FLD); operated at $250 \mathrm{~nm}$ excitation and $410 \mathrm{~nm}$ emission.

\section{Validation studies}

\section{Linearity}

The rat plasma samples were spiked by caffeic acid solutions having concentration 2.5, 5.0, 10.0, 25.0, 50.0 and $100.0 \mu \mathrm{g} / \mathrm{mL}$ and extracted as mentioned above. The resulting samples were analyzed in triplicate at the mentioned chromatography conditions. The response of the detector (peak height) was plotted against the respective concentration and linearity was evaluated visually by observing the correlation coefficient. 


\section{Recovery, accuracy and precision}

Three concentrations of caffeic acid solution (2.5, 50.0 and $100.0 \mu \mathrm{g} / \mathrm{mL}$ ) were used to determine recovery, accuracy and precision. After spiking the plasma and extraction, the three samples were analyzed in triplicate and amount of caffeic acid was determined from the calibration curve. The determined amount was compared to the true value (spiked amount) and presented as \% mean recovery $\pm \mathrm{SD}$.

For intraday accuracy and precision, each of the three standard solutions was analyzed in the same day for six times at chromatographic conditions mentioned above and the amount calculated from the calibration curve was compared to the true value to determine accuracy. Relative standard deviation was calculated as precision.

For inter day accuracy and precision, each of the three standard solutions was analyzed once daily for six consecutive days. The amount of the drug was determined from the calibration curve on each day. The determined values were used to assess accuracy and precision.

\section{Robustness}

The samples were analyzed by changing mobile phase composition ( $\pm 2 \%$ ), Column temperature $( \pm 1 \%)$ and detector parameters; excitation ( \pm 3 $\mathrm{nm})$ and emission $( \pm 3 \mathrm{~nm})$.

\section{Pharmacokinetic studies}

The study was conducted as per the research protocol approved by Animal Ethics Committee, University College of Pharmacy, University of the Punjab, Lahore, Pakistan (ref no. D/AEC/UCP/1027/4313).

\section{Animals}

Six, male, Wistar rats, weighing $200 \pm 10 \mathrm{~g}$, taken from University of Veterinary and Animal Sciences, Lahore, Pakistan, were allowed to acclimatize for seven days at Animal House, University College of Pharmacy, University of the Punjab, Lahore, Pakistan. Standard pellet diet and tap water were provided ad libitum. The animals were handled using Guideline 22 for the Housing of Mice in Scientific Institutions20.

\section{Dose preparation and administration}

The dried methanol extract having $74.27 \mathrm{mg} / \mathrm{g}$ caffeic acid was suspended in 1:1 (v/v) mixture of water and polyethylene glycol (PEG-400) to get a solution having concentration $250 \mathrm{mg} / \mathrm{mL}$. Then, $2 \mathrm{~mL}$ suspension (500 mg extract, equivalent to $37.135 \mathrm{mg}$ caffeic acid) was administered orally to each rat.

\section{Blood sampling}

From each rat, $0.5 \mathrm{~mL}$ blood was taken from the tail vein at $0 \mathrm{~h}$ (pre dose), 0.25, 0.50, 1.00, 2.00, 4.00 and $12.00 \mathrm{~h}$. The plasma was collected after centrifugation of blood at $2700 \mathrm{rpm}$ for $10 \mathrm{~min}$ at $25{ }^{\circ} \mathrm{C}$, which was then processed and analyzed as mentioned above.

\section{Determination of pharmacokinetic parameters}

Analytical data of each rat were used to plot a curve between plasma concentration of caffeic acid and time. Total area under the plasma concentration time curve $\left(\mathrm{AUC}_{0-\infty}\right)$ was calculated using the trapezoidal rule and as in Eqs 1 and 2.

$$
\begin{aligned}
& A U C_{0-\infty}=\sum\left(A C_{0-1}+A U C_{1-\text { last }}+A U C_{\text {last }-\infty}\right) \ldots \ldots \text { (1) } \\
& A \cup C_{\text {last }-\infty}=C_{\text {last }} / K_{\mathrm{el}}
\end{aligned}
$$

A plot between a cross product of concentration and time (CT) was used to calculate the area under the first moment curve (AUMC). Mean resident time (MRT) was obtained by dividing $A \cup M C_{0-\infty}$ with $A U C_{0-\infty}$.

The maximum plasma concentration $\left(\mathrm{C}_{\max }\right.$, $\mathrm{ng} / \mathrm{mL}$ ) and time to it $\left(T_{\max }\right)$ were taken directly from plot. The elimination rate constant $\left(\mathrm{K}_{\mathrm{el}}, \mathrm{h}^{-1}\right)$ was calculated by the linear regression on the terminal phase of the plasma concentration time plot and using Eq 3.

$\mathrm{K}_{\mathrm{el}}=\ln \mathrm{C}_{1}-\ln \mathrm{C}_{2} / \mathrm{T}_{2^{-}} \mathrm{T}_{1}$

The half-life $\left(t_{1 / 2}\right)$ was calculated by dividing 0.693 with $\mathrm{K}_{\mathrm{el}}$, while clearance $(\mathrm{Cl})$ and volume of distribution (VD) were determined as in Eqs 4 and 5 .

$\mathrm{Cl}=$ actual dose administered $/ \mathrm{AUC}_{0}$

VD $=$ Clearance/elimination rate constant

$\left(\mathrm{VD}=\mathrm{Cl} / \mathrm{K}_{\mathrm{el}}\right)$

\section{Statistical analysis}

The samples were analyzed in triplicate and the results were presented as mean \pm SD. The pharmacokinetics parameters were presented as mean of six rats \pm SD. 


\section{RESULTS}

\section{Plasma-extracted caffeic acid}

The method of extraction of caffeic acid from plasma was found to be appropriate because no interference of endogenous compounds of the plasma was observed (Figure 2 and 3 ). In this method, the retention time of caffeic acid was found to be $3.1 \mathrm{~min}$, which was lesser than some of the studies, wherein it was $10.9 \mathrm{~min}$ and 15 $\min [21,22]$. These results indicated that by using the present procedure, analysis could be completed in lesser time and consuming fewer solvents.

\section{Validity of the method}

The method was found to be linear in the whole range of samples investigated $(2.5-100.0 \mu \mathrm{g} / \mathrm{mL})$ with the linear regression equation $(\mathrm{Y}=$ $0.258+0.1744)$ and $R^{2}=0.9991$. This equation indicated that the plot was linear and the intercept was almost approaching to zero. Useful range was determined that could be used to quantify the drug in the samples. Moreover, peak symmetry and capacity factor indicated that the method was specific.

The results of LOD and $L O Q$ values of caffeic acid were found to be $0.70 \mu \mathrm{g} / \mathrm{mL}$ and 2.12 $\mu \mathrm{g} / \mathrm{mL}$, respectively, which indicated that the method was sensitive. The results of the recovery, intraday and inter day accuracy and precision are given in Table 1 . The mean recovery was found to be 96.09 - $98.43 \%$ with relative standard deviation less than $5 \%$. Intraday and inter day accuracy was found to be 96.09 - $98.43 \%$ and 90.86 - $97.93 \%$ respectively, with relative standard deviation less than $5 \%$. This indicated that the method was reliable, accurate and precise. Moreover, the method was found to be robust because it was not affected by a small change in mobile phase composition, column temperature and detection wavelengths.

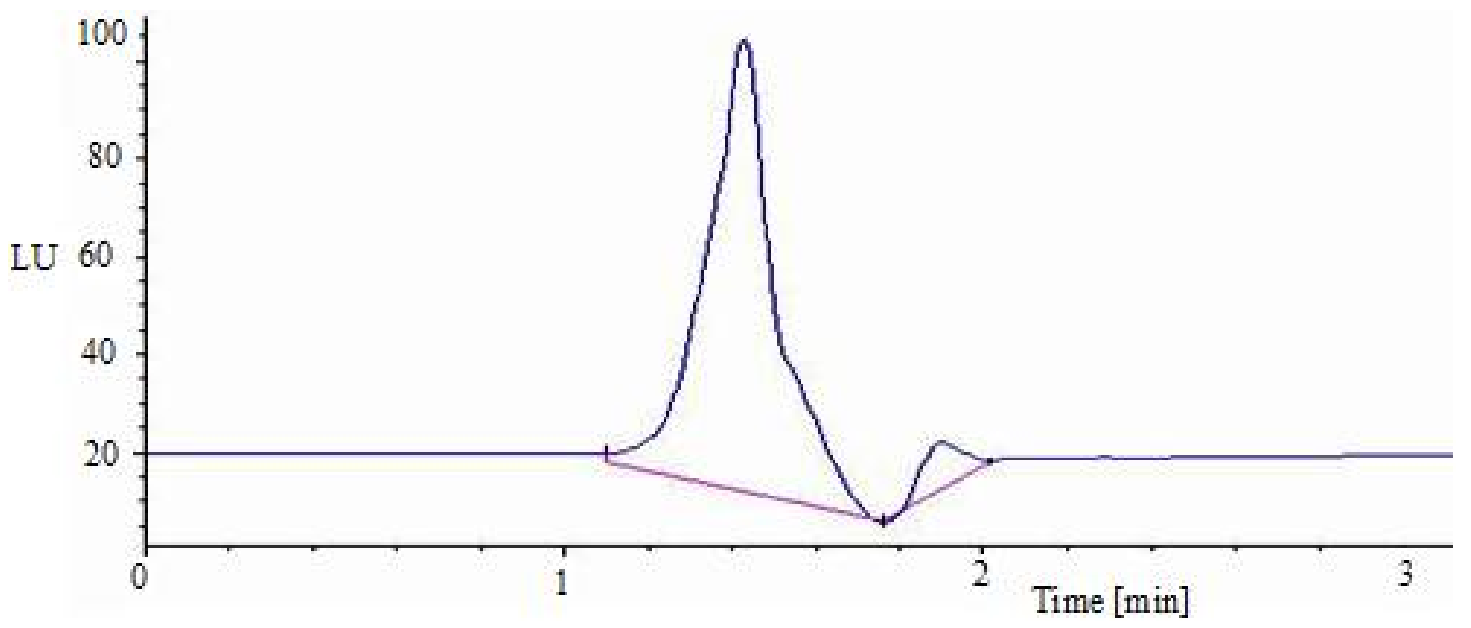

Figure 2: HPLC chromatogram of blank plasma

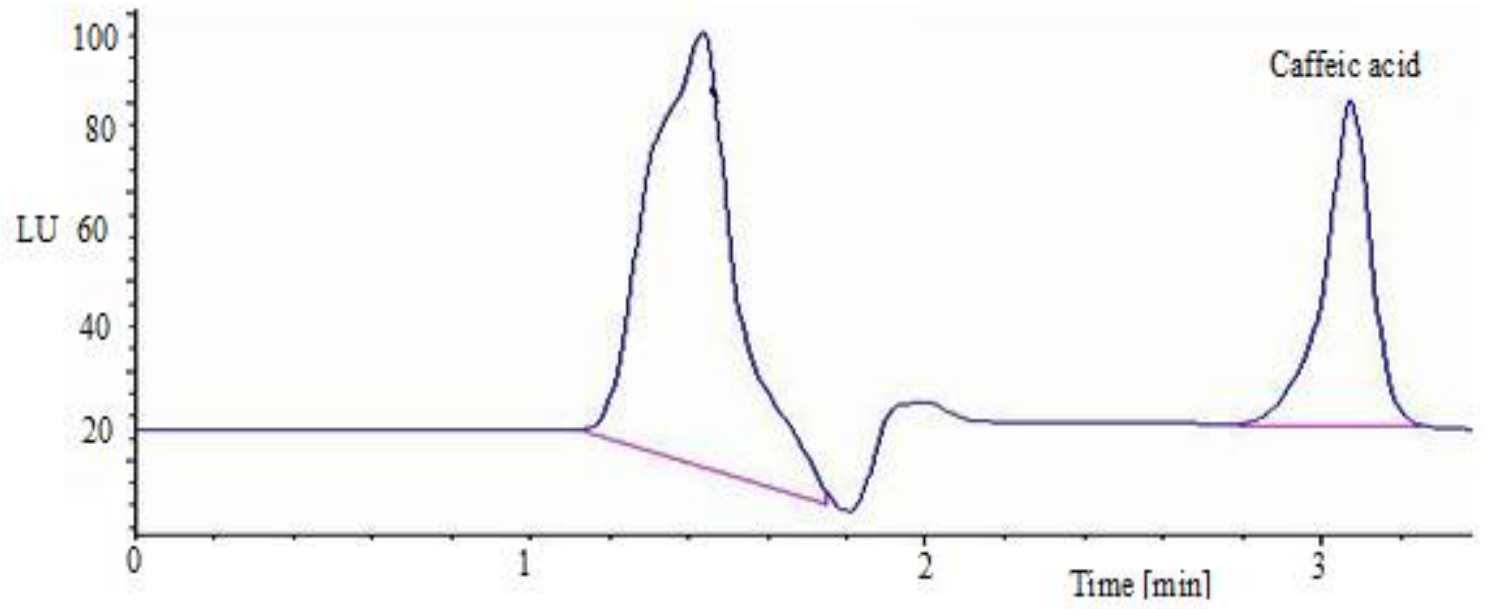

Figure 3: HPLC chromatogram of caffeic acid-spiked plasma 
Table 1: Recovery, intra-day and inter-day accuracy and precision of caffeic acid from spiked plasma by HPLC

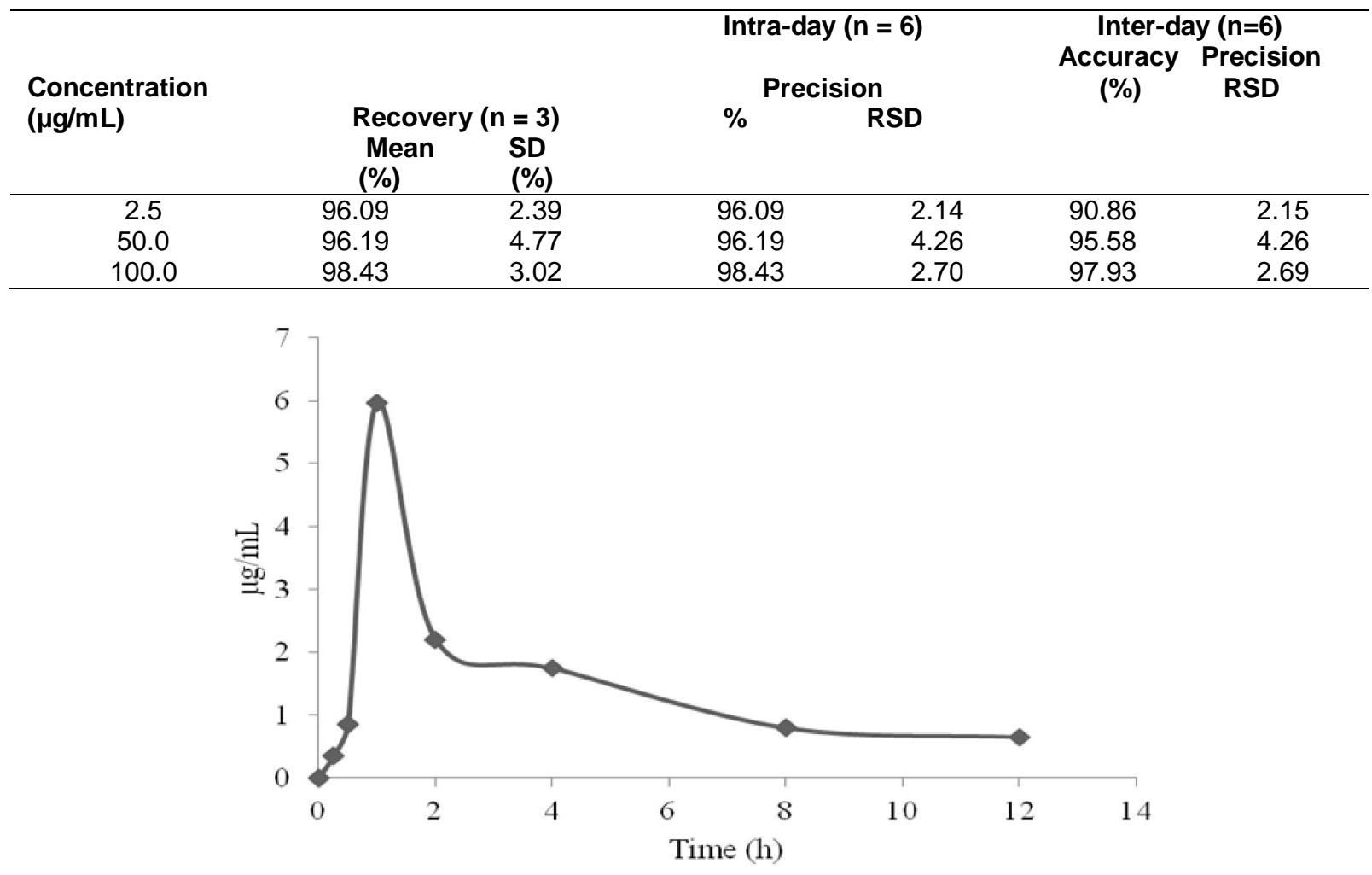

Figure 4: Plasma concentration of caffeic acid versus time plot; each point represents the mean of six rats

Table 2: Pharmacokinetic parameters of Syzygium cumini seed extract (based on caffeic acid, $\mathrm{n}=6$ )

\begin{tabular}{|c|c|c|}
\hline Pharmacokinetic parameter & Mean & SD \\
\hline Area under curve $0-12 \mathrm{~h}\left(\mathrm{AUC}_{0 \text {-last }}, \mu \mathrm{g} \cdot \mathrm{h} / \mathrm{mL}\right)$ & 17.88 & 1.98 \\
\hline Area under curve $0-\infty\left(\mathrm{AUC}_{0-\infty}, \mu \mathrm{g} \cdot \mathrm{h} / \mathrm{mL}\right)$ & 22.87 & 2.12 \\
\hline Area under mean curve (AUMC) & 73.16 & 11.95 \\
\hline Mean resident time (MRT, $h$ ) & 4.092 & 0.18 \\
\hline Half-life, $\left(T_{1 / 2}, h\right)$ & 0.14 & 0.01 \\
\hline Concentration maximum $\left(\mathrm{C}_{\max }, \mu \mathrm{g} / \mathrm{mL}\right)$ & 5.96 & 0.49 \\
\hline Time to achieve maximum concentration $\left(T_{\max }, h\right)$ & 1.00 & 0.00 \\
\hline Elimination constant $\left(\mathrm{Kel}, \mathrm{h}^{-1}\right)$ & 4.99 & 0.178 \\
\hline Clearance $(\mathrm{Cl})$ & 21.86 & 1.43 \\
\hline Volume of distribution (VD) & 4.378 & 0.16 \\
\hline
\end{tabular}

\section{Pharmacokinetic profile of caffeic acid}

The plasma samples of each rat, taken at different time intervals were analyzed to determine the contents of caffeic acid, which were then used to calculate various pharmacokinetics parameters. The plasma concentration versus time curve (Figure 4) indicated that caffeic acid of the extract followed a fast and steady absorption, which reached the maximum at $1.00 \mathrm{~h}$. The steady fall in the concentration from $1-2 \mathrm{~h}$ showed disposition of caffeic acid from the plasma to more perfused tissues. After $2 \mathrm{~h}$, elimination of the drug was found to be slow which indicated the excretion from plasma and dynamic equilibrium by moving the drug from tissue to blood.
The pharmacokinetics of caffeic acid is given in Table 2. These results showed that the absorption of caffeic acid from the oral route was quite fast, followed by a biphasic elimination. Mean resident time and volume of distribution (4 h) indicated that the body was exposed to the drug for a lesser time. The fast decline in concentration may be due to disposition or metabolism. In the present study, an oral dose of the extract (500 mg/rat), equivalent to 37.135 mg, was administered and a much lesser amount was absorbed $\left(\mathrm{C}_{\max }=15.2 \mu \mathrm{g} / \mathrm{mL}\right)$. Our results were found to be consistent to that reported earlier. The report indicated that $20 \%$ of the dose of caffeic acid was absorbed into enterocytes from the intestine, from where only 
$19.5 \%$ ( $0.5 \%$ secreted into the intestine) passed into mesenteric vein leading to the liver wherein the concentration was further decreased due to biliary secretion $(0.4 \%)$ resulting $19.1 \%$ bioavailability to peripheral tissues [21].

\section{DISCUSSION}

The separation of caffeic acid from rat plasma was achieved using solvent extraction. For such purpose, a combined approach- deproteination and liquid-liquid extraction- was employed. Deproteination was achieved using acetonitrile and extraction was carried out using methanol. The varying amounts of acetonitrile were used to achieve de-proteination. Acetonitrile $(200 \mu \mathrm{L})$ was found to be enough to de-protein $500 \mu \mathrm{L}$ of the rat plasma. Likewise, $800 \mu \mathrm{L}$ of methanol gave more than $95 \%$ recovery, which indicated that the method is good to be used to study pharmacokinetics of extracts of seeds of the plant. Moreover, the method was found to be accurate, precise and robust.

The drug must reach quickly at the site of action in a suitable concentration. At the same time drug must be eliminated from the body in lesser time to avoid the drug exposure. In the present study, caffeic acid absorption from the gastrointestinal tract was fast, but in lower amount than the dose administered (19.1\%). The clearance $(21.86 \mathrm{~h})$ and volume of distribution (4.378) indicated that the drug will be safer as the exposure was for a lesser time.

Caffeic acid is a well-known phenolic compound, which is widely distributed in fruits and vegetables [23]. The compound is reported to have significant antioxidant activity [24-26]. However, results of the present study indicate that oral bioavailability of this compound needs to be enhanced to get the maximum benefit.

\section{CONCLUSION}

The results obtained indicate the low but fast oral bioavailability of caffeic acid from the methanol seed extract of Syzygium cumini. Peak plasma concentration is achieved in $1 \mathrm{~h}$ which suggests improved oral absorption of caffeic acid.

\section{REFERENCES}

1. Khare CP. Encyclopedia of Indian Medicinal Plants. New York: Springer-Verlag; 2004; pp 207-208.

2. Kirtikar KR, Basu BD. Indian Medicinal Plants. New Delhi: Periodical Experts; 1975; pp 1052-1053.
3. Sagrawat H, Mann AS, Kharya MD. Pharmacological potential of Eugenia jambolana: A review. Pharmacog Magazine 2006; 2: 96-105.

4. Gordon A, Jungfer E, da Silva BA, Maia JGS, Marx F. Phenolic constituents and antioxidant capacity of four underutilized fruits from the Amazon region. Journal of Agric Food Chem 2011; 59: 7688-7699.

5. Bhuiyan MSA, Mia MY, Rashid MA. Antibacterial principles of the seeds of Eugenia jambolana. Bangladesh J Bot 1996; 25: 239-241.

6. Daisy P. Syzygium cumini (L.) skeels seeds with antibacterial and antidiabetic activity. 2007. Patent Application no. 810/CHE.

7. Mahapatra PK, Chakraborty D, Chaudhari AKN. Antiinflammatory and antipyretic activities of Syzygium cumini. Planta Medica 1986; 6: 540.

8. De Lima TCM, Klueger PA, Pereira PA, Macedo-Neto $W P$, Morato GS. Behavioural effects of crude and semi-purified extracts of Syzygium cumini L. skeels. Phytother Res 1998; 12: 488-493.

9. Jogetia GC, Baliga MS, Venkatesh P. Influence of Seed Extract of Syzygium cumini (Jamun) on Mice Exosed to Different Doses of Gamma-Radiation. J Radiation Res 2005; 46: 59-65.

10. Mauri F, Vast N, Pickard CJ. Atomic structure of icosahedral B 4 C boron carbide from a first principles analysis of NMR spectra. Phys Rev Lett 2001; 87: 085506.

11. Rath U, Wang D, Ding $Y, X u Y Z, Q i$, Blacketer MJ. Chromator, a novel and essential chromodomain protein interacts directly with the putative spindle matrix protein skeletor. J Cellul Biochem 2004; 93: 1033-1047.

12. Gurley BJ, Gardner SF, White LM, Wang PL. Ephedrine pharmacokinetics after the ingestion of nutritional supplements containing Ephedra sinica (ma huang). Therapeut Drug Monit 1998; 24: 439-445.

13. Li S, Han Q, Qiao C, Song J, Cheng CL, Xu H. Chemical markers for the quality control of herbal medicines: an overview. Chinese Med 2008; 3: 1-18.

14. Chen YJ, Shiao MS, Wang SY. The antioxidant caffeic acid phenethyl ester induces apoptosis associated with selective scavenging of hydrogen peroxide in human leukemic HL-60 cells. Anticancer Drug 2001; 12: 143149.

15. Park JH, Lee JK, Kim HS, Chung ST, Eom JH, Kim KA. Immunomodulatory effect of caffeic acid phenethyl ester in Balb/c mice. Int Immunopharmacol 2004; 4: 429-436.

16. Stojkovic D, Petrovic J, Sokovic M, Glamoclija J, KukicMarkovic J. In situ antioxidant and antimicrobial activities of naturally occurring caffeic acid, p-coumaric acid and rutin, using food systems. J Sci Food Agric 2013; 93: 3205-3208.

17. Jeong $\mathrm{CH}$, Jeong HR, Choi GN, Kim DO, Lee U, Heo HJ. Neuroprotective and anti-oxidant effects of caffeic acid isolated from Erigeron annuus leaf. Chinese Med 2011; 6: 1-9

18. Ayyanar M, Subash-Babu P, Ignacimuthu S. A review of its phytochemical constituents and traditional uses.

Trop J Pharm Res, February 2016; 15(2): 368 
Complementary Therapy and Medicine 2013; 21: 232243.

19. Dhungyal B, Koirala $P$, Sharma C. Jha DK. Caffeic AcidA Potent Phytocompound against Diabetes Mellitus $A$ Review. SMU Medical J 2014; 1: 152-160.

20. Fawcett A. (2012). Guideline 22: Guidelines for the Housing of Mice in Scientific Institutions. Animal Welfare Unit, NSW Department of Primary Industries.

21. Lafay S, Morand C, Manach C, Besson C, Scalbert A. Absorption and metabolism of caffeic acid and chlorogenic acid in the small intestine of rats. Brit $J$ Nutr 2006; 96: 39-46.

22. Konishi $Y$, Kobashi S. Transepithelial transport of rosmarinic acid in intestinal Caco-2 cell monolayers. Biosci Biotechnol Biochem 2005; 69: 583-591.
23. Manach $C$, Scalbert $A$, Morand $C$, Rémésy $C$, Jiménez $L$. Polyphenols: food sources and bioavailability. Am J Clin Nutr 2004; 79: 727-747.

24. Foley S, Navaratnam S, McGarvey DJ, Land EJ, Truscott $T J$, Rice-Evans CA. Singlet oxygen quenching and the redox properties of hydroxycinnamic acids. Free Rad Biol and Med 1999; 26: 1202-1208.

25. Laranjinha J, Cadenas E. Redox cycles of caffeic acid, alpha-tocopherol, and ascorbate: Implications for protection of low-density lipoproteins against oxidation. Int Union Biochemistry Mol Biol Life 1999; 48: 57-65.

26. Natella F, Nardini M, Giannetti I, Dattilo C, Scaccini C. Coffee drinking influences plasma antioxidant capacity in humans. J Agric Food Chem 2002; 50: 6211-6216. 